\title{
EXPERIMENTAL STUDY OF THE FLOW DYNAMICS OF COMPLEX VISCOELASTIC FLUID THROUGH HYPERBOLIC CONTRACTION/EXPANSION
}

\author{
Muñoz Garduño Kevin David* \\ Universidad Nacional Autónoma de México, Facultad de Estudios Superiores Zaragoza \\ Batalla 5 de mayo S/N, Ejercito Oriente, Iztapalapa, 09230 Ciudad de México, México.
}

\author{
Pérez Camacho Mariano* \\ Universidad Nacional Autónoma de México, Facultad de Estudios Superiores Zaragoza \\ Batalla 5 de mayo S/N, Ejercito Oriente, Iztapalapa, 09230 Ciudad de México, México.
}

Article DOI: https://doi.org/10.36713/epra5875

\begin{abstract}
The main objetive of this work was to experimentally study the Flow dynamics of viscoelastic fluids (Boger fluid and Hase) when they flow through a contraction/expansion system defined by a hyperbolic tube, therefore through equations analogous to the Hagen-Poiseuille equation, the pressure drop associated with the viscous interaction was quantified, and subsequently the excess pressure drop (EPD), a parameter associated with the elasticity of viscoelastic fluids, conducting comparative studies with respect to a Newtonian reference for the same shear viscosity value, which allowed observing shear speed intervals where three predominant zones were observed. The first of them of shear type coinciding with the trajectories of the Newtonian fluid of identical viscosity value, the second zone was attributed to the elastic manifestation of the fluids due to the preferential development of the extensional flow that is in constant competition with the shear flow within of the same geometry. The third zone was attributed to a predominance of the shear flow over the extensional one, because of to the fact that the hyperbolic geometry favors the development of this type of flow at high values of shear rate
\end{abstract}

KEYWORDS: Excess pressure drop; Extensional flow; Hyperbolic contractions

\section{BACKGROUND}

The first studies of flows in contraction with viscoelastic fluids can be considered to have been carried out by Cable \& Boger (1978) analyzing the flow through axisymmetric contractions at different contraction ratios with two fluids: the first based on glucose and polyacrylamide, and the second a polyisobutene / polybutene mixture. Their results showed that the flow conditions in the contraction were mainly due to the rheological characteristics of the fluid, with all the information obtained they carried out specific velocity studies along the radial axis in the vicinity of the contraction, with 2: 1 and 4: 1 ratios using polyacrylamide solutions where they observed a deceleration in the central line of flow of which had no explanation until that moment

The presence of extensional flow which gave rise to a uniaxial extensional viscosity, was responsible for this unknown behavior causing different responses in viscoelastic fluids for the same contraction and shear rate, meant an advance in the understanding of the dynamics flow in a contracting system.

Cable and Boger defined two main zones: the vortex growth regime and the divergent regime; with the which the presence of a shear flow and an extensional flow was reflected early as well as the 


\section{SJIF Impact Factor: 7.001| ISI I.F.Value:1.241| Journal DOI: 10.36713/epra2016 ISSN: 2455-7838(Online) EPRA International Journal of Research and Development (IJRD)}

participation of both phenomena in the flow dynamics. In a later analysis (Boger, 1987), he attributed the change in flow conditions to an uneven development of extensional viscosity, to the same contraction ratio. Nguyen and Boger (1979) indirectly showed the presence of a shear flow in the contraction.

Binding (1991) in his proposal of flow dynamics, considered two aspects: the dominant flowin the fluid when passing through the contraction, and the elastic effect of the solution, fromthe first difference of normal stress. For this he proposed two mechanisms: a quasi-radial flow present at low values of shear rate, it considers that the flow has a radial contribution, in addition to that carried in the axial direction, which has its origin in the elastic nature of the fluid developing a shear flow even above extensional flow And a funnel type flow at high values of shear speed where the current lines are oriented towards the interior of the contraction, favoring the development of the uniaxial extensional flow. These zones correspond to the regimes exposed by Cable and Boger.

Meissner (1985), Coswell (1987), James (1990, 1991) are the first to expose the use of convergent hyperbolic geometries in contracting flows, since they comply with areas where the product of the square of the radius times the length of the geometry are constant. This condition would guarantee the formation of an extensional flow free of shear effects.

The main areas in which the investigations of flow in hyperbolic contraction are focused are given in the study of planar geometries where the threedimensional effects are not considered significant. In recent years, expansion-contraction studies have focused in addition to sudden axisymmetric contraction towards other types of geometry such as hyperbolic in order to find the differences caused by the geometry on the flow dynamics. Works such as those presented by Oliveira (2006) , Campo (2011), Ober (2013) and collaborators deal with planar hyperbolic contraction zones with different types of viscoelastic fluids modeled by different constitutive equations (PTT / Carreau); These are performed on a micrometric scale and their results are restricted to small flow ranges and shear rate.

Tabatabaei (2015) studied the flow of micellar fluids in an axisymmetric hyperbolic contraction/expansion in a numerical way, using the finite volume method; while Nyström (2016) makes a numerical / experimental comparison of a Newtonian fluid and a Boger fluid on a millimeter scale, finding great similarities between their results. The characteristic radial function with which the contraction zone is defined takes on special relevance since it is an indicator of the fluid-wall interaction generated, being greater compared to a sudden contraction of similar dimensions.

Many of the previous studies lead to the conclusion that the viscous effects due to shear arethe main contribution in the total pressure drop generated by these systems, therefore any additional effect is seen as a result of the elastic and extensional response by fluid. There have been many authors who, through numerous models and constitutive equations (James(1991), Rajagopalan (2000), Feigl (2003), Pandey (2007), Sousa (2010-2011)), who have proposed decoupling the effects viscosity of the extensionals, to determine the values associated only with the extension, such as the extensional viscosity of an inhomogeneous flow field, with acceptable results, but restricted to very low extension speed values, given that most of the devices The proposed experiments are carried out at the micro and nanometric scales. However, larger-scale flows represent the cases present in a large number of situations both within and outside the field of engineering, far from ideal situations. In this sense, Binding and Walters (1988) have spearheaded the idea that generating a purely extensional flow is practically impossible.

Despite this situation, there are still many proposals in order to decouple flows with a high extensional component from their shear part and thus be able to interpret the data in a way that can capture the extensional component adequately and accurately, defining the speed of deformation and extensional viscosity. These statements have been debated and controversial by the scientific community of the field, given their importance and the expectation of being able to make semi-quantitative predictions.

\section{HYPERBOLIC CONTRACTION EXPANSION}

The hyperbolic contraction/expansion geometry, despite its simplicity, shows a great variety of flow paths that depend from the rheology of the fluid used and the type of hyperbolic path studied or even if the geometry is rectangular or cylindrical. Like axisymmetric and square geometry during flow development, competition occurs spontaneously between the shear flow that manifests itself in the vicinity of the contraction walls and the uniaxial extensional flow that develops mainly on the central line.

When the fluid enters the geometry, it imposes flow conditions that cause very different fluid responses depending of the rheology of the fluid, for example if the experiment is carried out at constant flow, as the flow develops, the fluid experiences a differential acceleration through a length differential, 


\section{SJIF Impact Factor: 7.001| ISI I.F.Value:1.241| Journal DOI: 10.36713/epra2016 ISSN: 2455-7838(Online) EPRA International Journal of Research and Development (IJRD)}

due to the reduction in area, this condition is maintained until reaching the smallest area of the geometry which is just in the middle part to start the phenomenon again in the direction inverse, that is a expansion process.

Since of the rheological point of view, the fluid exposed to a hyperbolic contraction-expansion, in its contraction stage experiences an increase in its shear rate also differentially, if the fluid is Newtonian in nature its response will be exclusively of viscous origin which will develop along the walls of the contraction, however since the area differentially decreases the viscous response of the fluid will decrease to become more and more in a inertial response which will have its greatest presence right in the center of the contraction, this effect has been visually registered by observing vortices of non-elastic origin in the vicinity of the median plane of contraction, as reported be Campo Deaño 2013

If it is a viscoelastic fluid of constant viscosity such as Boger fluid, the competition between the viscous response from the strong development of the shear flow in relation to the response of inertial origin is very uneven unless the inertial forces develop due to the provision of high flows which will generate high speeds. what is preferentially presented is the development of high extensional stresses in the vicinity of the central line of the contraction that favor the development of the extensional flow, which is now strongly favored because this geometry directs the streamlines towards the central line just up to half the geometry.

Undoubtedly, now the competition between the development of the uniaxial extensional flow and the shear flow is important to understand the flow dynamics, in particular for a Boger fluid since its viscosity associated with the shear flow will remain constant at any value of shear rate imposed on the system but not its viscosity associated with the development of extensional flow of an elastic nature which will inevitably increase as the flow in the system increases.

In addition to this competence and keeping in mind the study of flow dynamics, the presence of the first normal stresses from the development of the shear flow in this geometry is important, since as it has been studied in previous contractions, their presence is decisive in the dynamics flow especially at the beginning of experimentation at low shear rate values.

If it is a study of the flow dynamics of a viscoelastic but thinning fluid, its response to flow now involves one more effect in relation to the response of a Boger fluid, The thinning nature will cause a decrease in viscosity in a differential way as the shear rate is increased along the geometry, this condition substantially reduces the presence of the shear flow, allowing a greater development of the extensional flow, However, the presence of N1 in shear does not change due to the fact that the viscosity of the fluid decreases, hence in this study two types of competencies will be presented: at low values of shear rate, the development of extensional flow competes so much with the development of the shear flow even with a high viscosity value together with its elastic manifestation corresponding to the first difference of normal stresses

At relatively high values, the competition between opposite effects, the competition will be between a very intense extensional flow with a very decreased shear flow where the viscosity of the fluid will reach values as low as that of the solvent, however with an elastic response associated with the shear very intense whose shear stresses will be in magnitude very similar or even greater than the extensional stresses developed on the center line.

Once the fluid crosses the middle part of the geometry, the high competition between both flows relaxes in the case of a Boger fluid, the extensional flow relaxes and therefore its viscosity while its shear viscosity will still remain constant, for the case of the elastic and thinner fluid such as HASE the shear viscosity gradually recovers as the fluid completes its path through the geometry, while the viscosity associated with the extensional flow will decrease due to the relaxation of the fluid and the increase in shear viscosity.

Against this background, the experimental capture of the competition between both flows in both the convergent and divergent sections of the geometry is important in understanding the flow dynamics of complex fluids in hyperbolic contractions-expansions.

\section{THEORETICAL FRAMEWORK} Pressure Drop Through a Hyperbolic Tube

One of the main challenges in the study of hyperbolic contractions is to find an analytical expression that describes the pressure drop through tubes with this type of geometry. Sochi (2010), proposed a method to calculate the pressure drop of a Newtonian fluid in tubes of non-constant radio in an analytical way, from the Hagen-Poiseuille Equation, and with it applying all the considerations associated with obtaining it. (Bird, 1960).

The pressure drop experienced by a Newtonian fluid flowing through a straight tube of radius $r$ along a distance $\mathrm{L}$ is calculated using the Hagen-Poiseuille 


$$
\Delta P=\frac{8 Q L \mu}{\pi r^{4}}
$$

For an infinitesimal length and defining a radial function $\mathrm{r}(\mathrm{x})$, dependent on the length of the tube $\mathrm{L}$

$$
\Delta P=\frac{8 Q \mu}{\pi} \int_{x=0}^{x=L} \frac{d x}{r(x)^{4}}
$$

In this work the hyperbolic function with a radial function proposed by Tabatabaei (2015) will be used

$$
r(x)=\frac{r_{\text {max }}}{\sqrt{\left(\frac{x}{15 r_{\text {min }}}\right)\left(\frac{r_{\max }^{2}}{r_{\text {min }}^{2}}-1\right)+1}} 0 \leq x \leq 15 r_{\text {min }}
$$

Substituting Eq. 3 in Eq. 2 and later integrating

$$
\Delta P_{C}=\frac{80 Q \mu}{\pi r_{\max }^{4}}\left[r_{\min }+\frac{r_{\max }^{2}}{r_{\min }}+\frac{r_{\max }^{4}}{r_{\min }^{3}}\right]
$$

which corresponds to the pressure drop of a Newtonian fluid through a hyperbolic geometry.

Pressure drop measurements are not made directly at the inlet or outlet of the hyperbolic geometry, so the reading is not affected by inlet effects as well as nearby vortex formation.

To minimize these effects, straight tube sections are considered in the areas immediate to the entrance and exit of the hyperbolic geometry as shown in Fig.1 from which the measurement sensors are located (the radius of these straight sections must correspond to the maximum radius of the contraction /expansion hyperbolic).

\section{Excess Pressure Drop (EPD)}

The total pressure drop for a Newtonian fluid estimated experimentally as shown in Fig.no.1 does not correspond exactly to the sum of the individual pressure drops, for this it is necessary to incorporate the known excess pressure drop (EPD) that corresponds to the difficulty experienced by the fluid at the entrance of the contraction for the case of a Newtonian fluid has been addressed by Sampson for the case of axisymmetric geometries ( ), however for hyperbolic geometries for Newtonian and non-Newtonian fluids its expression is still unknown by which must be estimated experimentally. 


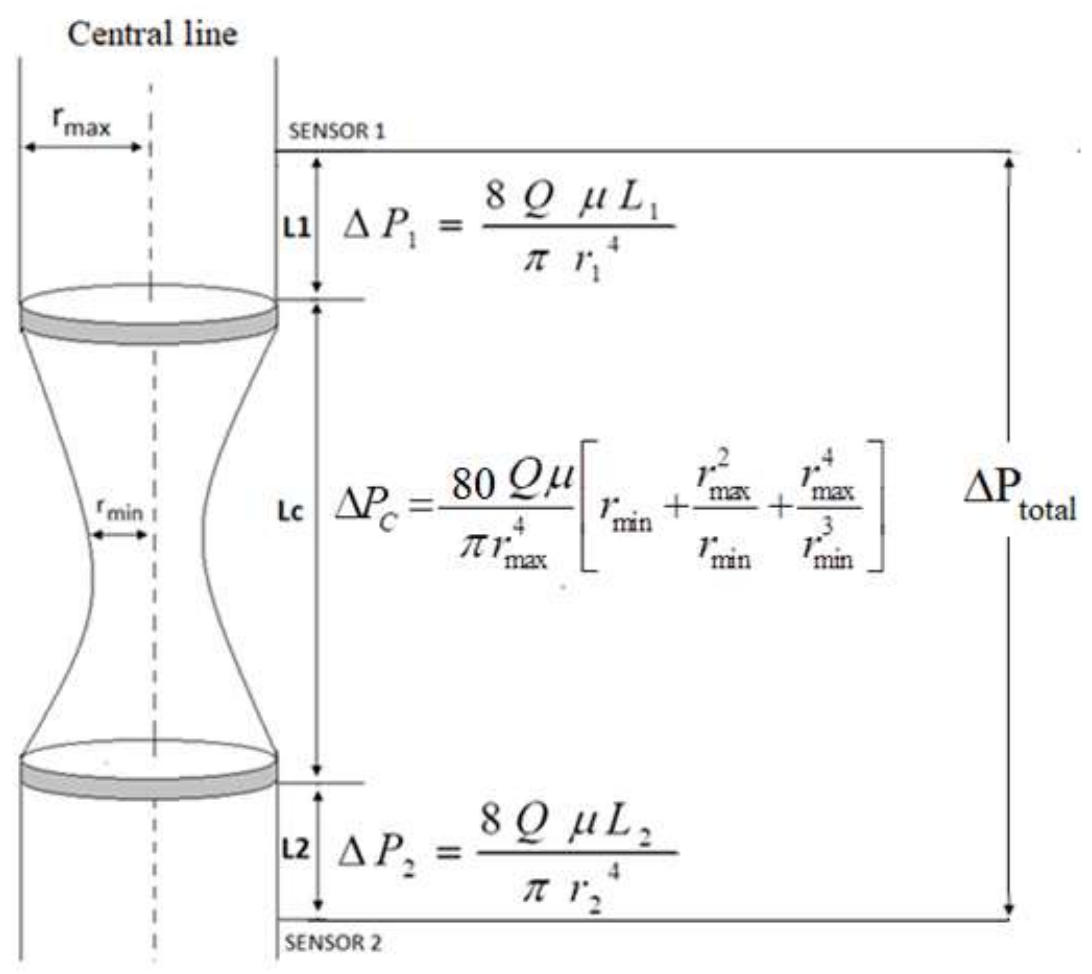

Fig. no.1 Partial and total pressure drops through a hyperbolic contraction /expansion system

For the estimate of the total experimental pressure drop to coincide with the sum of the partial pressure drops illustrated in Fig. 1, it is necessary to consider the excess pressure drop

$$
\Delta P_{\text {Total }}=\Delta P_{1}+\Delta P_{C}+\Delta P_{2}+\Delta P_{e}
$$

The excess pressure drop has a different interpretation depending on the type of the fluid, for a Newtonian fluid, the EPD represents the resistance to flow of viscous origin that the fluid experiences at the entrance of the contraction, while for a viscoelastic fluid it is considered as that flow condition that promotes the development of extensional flow within the contraction (Cogswell, 1978), This term is usually obtained indirectly, from experimental total pressure drop readings of the system

$$
\begin{gathered}
\Delta P_{e}=\Delta P_{\text {Total }}(\exp )-\left(\Delta P_{1}+\Delta P_{C}+\Delta P_{2}\right) \\
\Delta P_{e}=\Delta P_{\text {Total }}(\exp )-\left[\frac{8 Q \mu(L 1+L 2)}{\pi r_{\text {max }}^{4}}\right]-\left[\frac{80 Q \mu}{\pi r_{\text {max }}^{4}}\left(r_{\text {min }}+\frac{r_{\text {max }}^{2}}{r_{\text {min }}}+\frac{r_{\text {max }}^{4}}{r_{\text {max }}^{3}}\right)\right]
\end{gathered}
$$




\section{EPRA International Journal of Research and Development (IJRD)}

Volume: 5 | Issue: 12 | December 2020

- Peer Reviewed Journal

\section{Experimental determination of extensional viscosity}

As stated above, much research is focused on finding new techniques and devices for the determination of extensional viscosity. The main difficulty lies in obtaining and generating conditions that promote the formation of a purely extensional flow with constant extensional rate (Trejo, 2013). Contraction and / or contraction / expansion flow systems have been proposed by many researchers as a way to accomplish this goal, given their relative simplicity and being able to calculate this quantity in terms of simpler variables such as pressure drop, volumetric flow, and other material and / or geometric parameters

One of the main examples to expose the difficulty of obtaining the extensional viscosity is the so-called M1 project, where through various techniques and methodologies, they determined the value of the extensional viscosity of a standard polymeric solution, called M1. (Petrie, 2006). There are many discrepancies in the experimental values of extensional viscosity. This is a trend that continues even in more recent similar techniques. The determination of the quantity $\tau_{z z}-\tau_{r r}$ has been one of the main topics in studies on the subject. The proposals for the determination of extensional viscosity in contracting systems have been diverse, such as the experimental measurement of the total pressure between the inlet and outlet of a hyperbolic contraction, in addition to the extension rate $\varepsilon$ ' and the Hencky extension $\varepsilon_{h}$ ( Feigl Et Al, 2003)

$$
\eta_{e}=\frac{\Delta P_{e}}{(\dot{\varepsilon})\left(\varepsilon_{h}\right)}
$$

Alternatively, the value of the first normal stress difference $\mathrm{N} 1$ is also proposed as a parameter to obtain it; an example of this is the work of Nystorm. (2016). The differences in the value of extensional viscosity between researchers are not few: Ober (2013) and Wang (2011) obtain extremely high extensional viscosity values when compared with the shear viscosities of the study fluids, giving rise to high Trouton ratios, while Anna (2000) and James (1991) show extensional viscosities in their work that meet the Trouton relationship at low flows.

One of the main reasons to explain this disparity between results and magnitudes of extensional viscosity in different experiments lies in the magnitude of the extension speed, which is usually very low with respect to the order of magnitude of the pressure, which causes the value of extensional viscosity increases exponentially. Alternatives have been proposed, such as associating the Hencky extension or the pressure coefficient (James \& Chandler, 1991) to the calculation of the extensional viscosity to correct this effect and offer values closer to those of the predicted theoretical viscosity. Some of the interpretations presented by Ober (2013) to explain the non-fulfillment of the
Trouton relation in their results mentions that the measurements made do not represent an ideal homogeneous extensional flow, but rather a dominant transient flow in extension, being affected by the behaviors rheological fluid, so Quantities such as excess pressure drop and extensional viscosity are considered a measure of the viscoelastic resistance to expansion in mixed flow rather than a pure elastic manifestation.

\section{EXPERIMENTAL METHODOLOGY Construction of contractions}

The modeling of the hyperbolic contraction/expansion zones for different contraction ratios was carried out in the free access software Blender, respecting the dimensions given by the radial function (equation 3). Later they were built by a 3D printer (figure 2). The impression material was acrylonitrile-butadiene-styrene (ABS).

Table 1 shows the dimensions of each of the contractions studied. 
Table 1. Dimensions for hyperbolic contractions

\begin{tabular}{cccc}
\hline Contraction ratio & $\begin{array}{c}\text { Maximum } \\
\text { radius }[\mathbf{c m}]\end{array}$ & $\begin{array}{c}\text { Minimum } \\
\text { radius }[\mathbf{c m}]\end{array}$ & L=30*Rmin [cm] \\
\hline $2: 1: 2$ & 1 & 0.5 & 15 \\
$3: 1: 3$ & 1 & 0.33333 & 10 \\
$4: 1: 4$ & 1 & 0.25 & 7.5 \\
$5: 1: 5$ & 1 & 0.2 & 6 \\
\hline
\end{tabular}

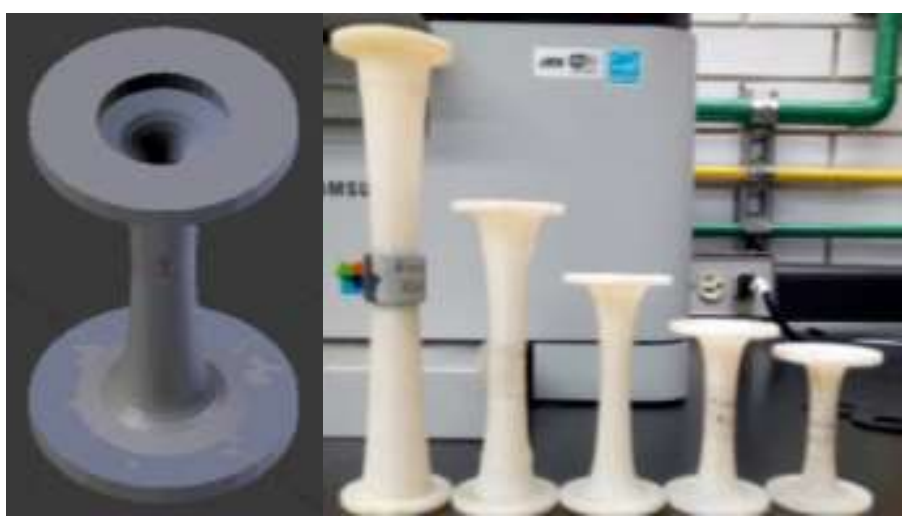

Figure 2. 3D-model and final impressions at different contraction ratios

\section{$(2: 1: 2,3: 1: 3,4: 1: 4,5: 1: 56: 1: 6)$}

\section{Rheology of solutions}

Three fluids with different rheological properties were prepared, where the proportion of their components guarantees that all of them present the same value of shear viscosity $16 \mathrm{~Pa}$ s at the established operating temperature $\left(26^{\circ} \mathrm{C}\right)$ and whose procedures are exposed in greater depth in previous works (Pérez, 2016; Quezada, 2017)

Newtonian fluid used as a reference fluid, consists of a concentrated solution of 10 liters of glucose in water, which were equally separated to use in the preparation of Boger fluid.

To the remaining concentrated glucose solution, add a small amount of dilute polyacrylamide solution. The addition of this polymer generates a fluid whose viscous behavior is like that of a Newtonian fluid, while exhibiting elastic properties (Boger fluid). $50 \mathrm{ml}$ of a $0.1 \%$ by weight solution of polyacrylamide in water were prepared.

Finally, a HASE (hydrophobically modified alkali-swellable emulsion) is made up of polymer chains that form micellar structures. This structure gives it its main rheological properties: at low shear rate values, the shear viscosity remains constant, at a higher shear rate it begins to show a shear-thinning behavior. For the preparation of this fluid, $500 \mathrm{ml}$ of a $0.1 \mathrm{M}$ solution of neutralizing agent and 2-amino-2methyl-1-propanol was used, allowing it to stand at room temperature for 24 hours. 5 liters of $2.5 \%$ HASE solution were prepared, for this Acrisol TT-935 was used, slowly adding distilled water, which received mechanical stirring for 30 minutes and then left to rest for 72 hours. 


\section{EPRA International Journal of Research and Development (IJRD)}

Volume: 5 | Issue: 12 | December 2020

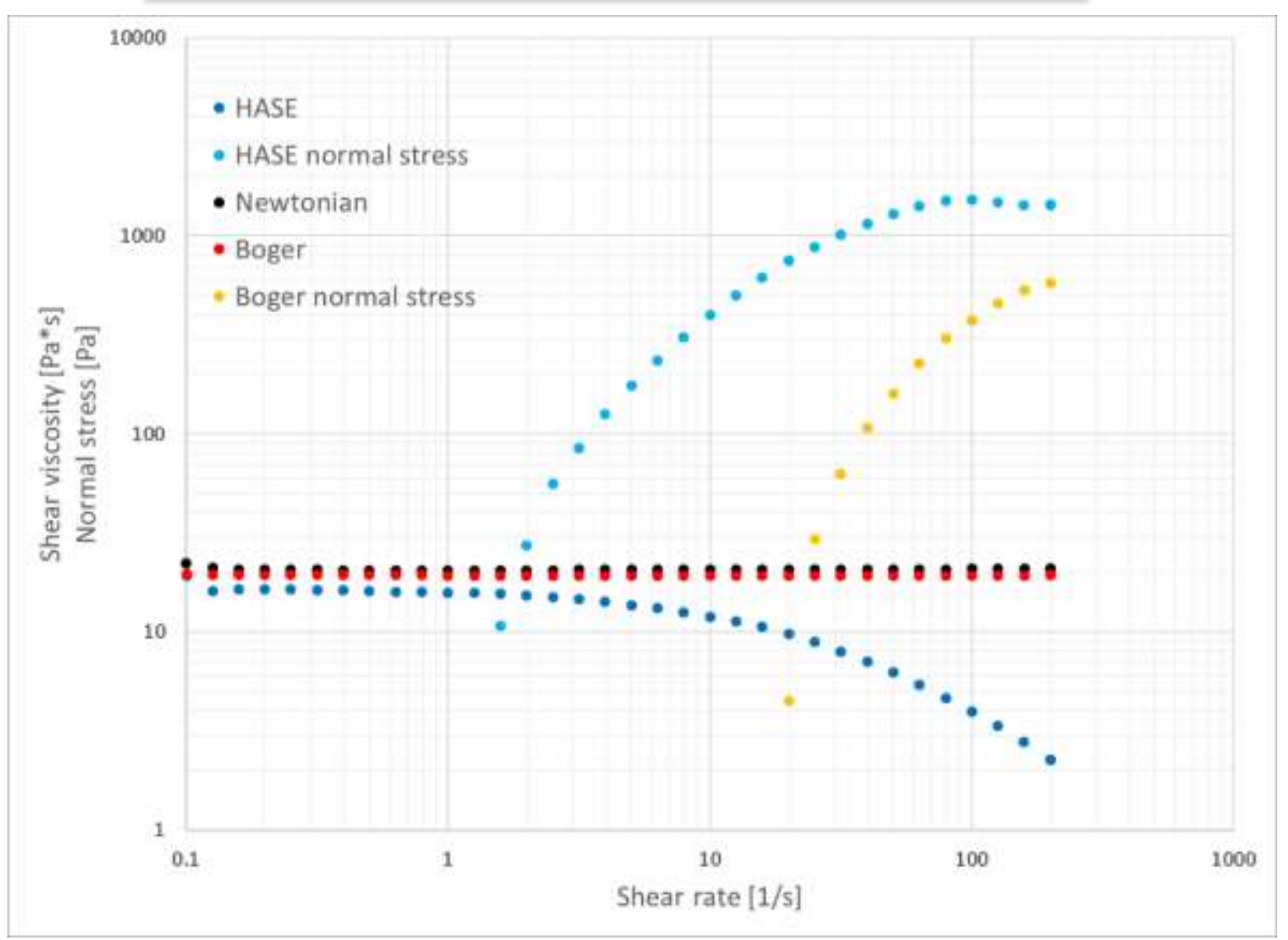

Figure 3. Rheogram for the different fluids for the experimental phase at operating temperature $\left(26^{\circ} \mathrm{C}\right)$

The shear viscosity values, as well as the elastic response of the fluids, were measured an AR-G2 cone and plate rheometer from TA Instruments.

\section{RESULTS AND DISCUSSION \\ Contraction 2: 1: 2 \\ Total pressure drop vs shear rate}

At low shear rate values, the three fluids present a similar upward trend, characteristic of a shear flow (figure 4-a); While the Newtonian fluid follows this behavior throughout the entire experimentation range, for the two viscoelastic fluids there is a critical shear rate (5-6 s-1), where the pressure drop increases considerably with respect of the Newtonian fluid. increasing the shear rate, the HASE solution present a slight decrease, indicating changes in the value of its shear viscosity, predicted by its rheological behavior (figure 3).

-Excess pressure drop vs shear rate

The excess pressure drop (EPD) allows to visualize the elastic contribution present in the fluids to be analyzed, as they are separated from their shear counterpart. The graph in figure 4-b shows how both the Boger fluid and the HASE solution do not present values close to the Newtonian shear behavior at low flows, concluding that even in this range of values elasticity develops to a greater or lesser degree, (phenomenon not observable in the graph of total pressure drop) and it is until the critical shear rate is reached that the elastic effect increases dramatically. At high shear speed values, the growth of the elastic effect is no longer increasing, with trends like those observed at low flows: shear flow begins to hinder the development of extensional flow.

In the case of the Boger fluid, the value of the EPD presents values below the Newtonian line, contradicting what was previously stated regarding the development of elasticity at low flows, especially when compared with the HASE solution, whose values are always above the Newtonian line. The study of dimensionless quantities will make it possible to visualize the effects associated more clearly. 


\section{SJIF Impact Factor: 7.001| ISI I.F.Value:1.241| Journal DOI: 10.36713/epra2016 ISSN: 2455-7838(Online) EPRA International Journal of Research and Development (IJRD)}

\section{Dimensionless excess pressure drop vs shear rate}

As stated previously, dimensionless EPD provides a comparison between the extensional flow developed by viscoelastic fluids and the resistance of the fluid to flow through the contraction zone. So, any value greater than unity is associated with an extensional response of elastic origin

The corresponding graph (figure 4-c) shows interesting behaviors that occur in viscoelastic fluids at low shear rates. The fluids start with values greater than the reference (an indication that there is indeed an elastic effect), presenting a decrease to a minimum value, and subsequently grow as they approach the critical shear rate; This behavior is caused by the manifestation of the first difference in normal stresses, that is, the effect of the elasticity of the fluid in the direction perpendicular to the flow, which hinders the total development of the extensional flow in the axial direction, and increasing the shear flow effect.

As flow increases, the elastic effect in the axial direction begins to dominate over the elastic effect in the radial direction and thus the dominance of extensional flow. However, upon reaching a maximum point, the extensional domain is not maintained, decreasing again with increasing shear rate, indicating greater resistance to flow.

There are some particular differences between the fluids studied: The values of dimensionless EPD at low shear rates are higher in HASE (the elasticity of this fluid is usually higher) as well as the maximum value generated in the vicinity of the critical shear rate (area where there is the maximum extent of the fluid). The decrease observed in the zone after the critical shear rate in HASE is more noticeable than Boger.

An explanation for these differences is found in the very nature of the HASE solution, since it consists of long polar molecular chains, which favor the orientation of its molecules with the flow, from a certain point, the oriented chains begin to interact strongly with each other, increasing the shear flow effect. In the case of the Boger fluid, the decrease from the maximum point is smaller, since its molecules do not tend to interact with each other in the same way as HASE, so its decrease is related to a predominance of shear flows.

Analogous to the previous graph, the quotient between the excess pressure drop and the pressure drop of the hyperbolic geometry (Figure 4-d) directly compares the extensional and shear flows present in the fluid. The line for Newtonian fluid shows that flow experiences a shear flow domain. The variations presented by the viscoelastic fluids with respect to the Newtonian line will be related to the development of the extensional flow.

The viscoelastic fluids present a behavior like that analyzed in the first dimensionless EPD graph, observing the effect of the first difference in normal stresses of the two fluids. However, the previous graphs provide additional information: the shear flow has different origins depending on the area being studied: at low shear rate the shear effect has an elastic origin, carried out in a direction perpendicular to the flow, while at higher shear rate, the shear effect is due to the viscous interaction of the fluid (both with the tube walls and between the fluid elements) increasing its resistance to flow.

In the middle of these two zones, there is a relatively small shear rate range (the only one observed) where the extensional effect exceeds the shear flow. A study focused on the extensional flow should focus on analyzing an ranges of shear rate close to the critical value.

\section{Extensional viscosity vs extension rate}

The calculated extensional viscosity values (figure 10-e) for the two fluids show very high values when compared with their respective shear viscosities (figure 10-f); although they are consistent in order of magnitude to that of studies with similar methodologies (Aguayo, 2008; Wang, 2011; Ober, 2013). As occurs in the graphs referring to the shear rate, there is a critical extension rate $(0.06-0.081 / \mathrm{s})$, where the property growth grows drastically, which coincides with the area of predominance of the extensional flow in the system. At extension speeds after the critical zone, a decrease in extensional viscosity is observed, consistent with a greater influence of the shear flow, being more noticeable in HASE, while the Boger fluid exists an interval where it remains practically constant. These differences are caused by the change in viscosity of HASE as the shear effect in the flow increases, therefore, as its shear viscosity decreases, the same trend is observed for its extensional counterpart 


\section{FIGURE 4. EXPERIMENTAL RESULTS - CONTRACTION/EXPANSION 2:1:2}

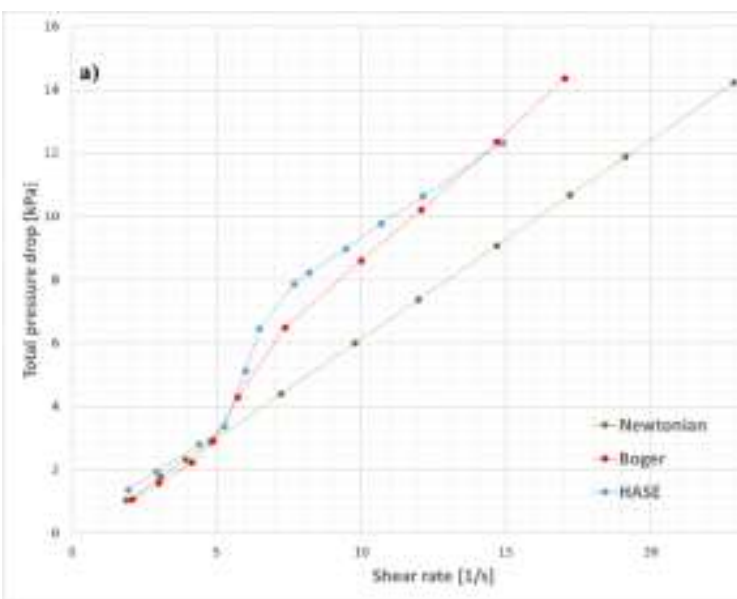

a) TOTAL PRESURE DROP VS SHEAR RATE

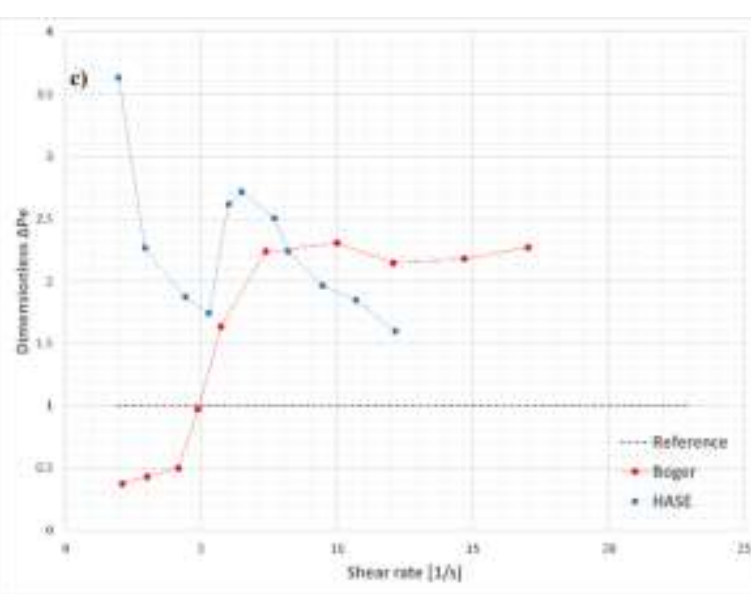

c) dimensionless EPD vs shear rate

e) Extensional viscosity vs extensión rate

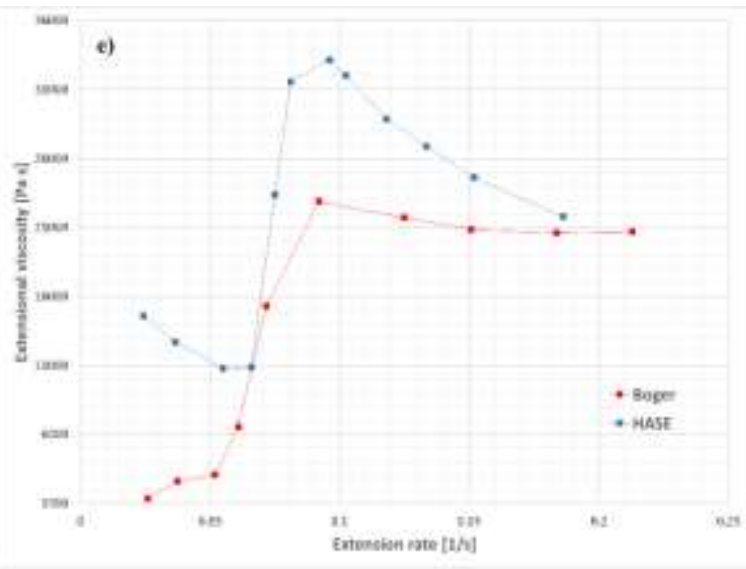

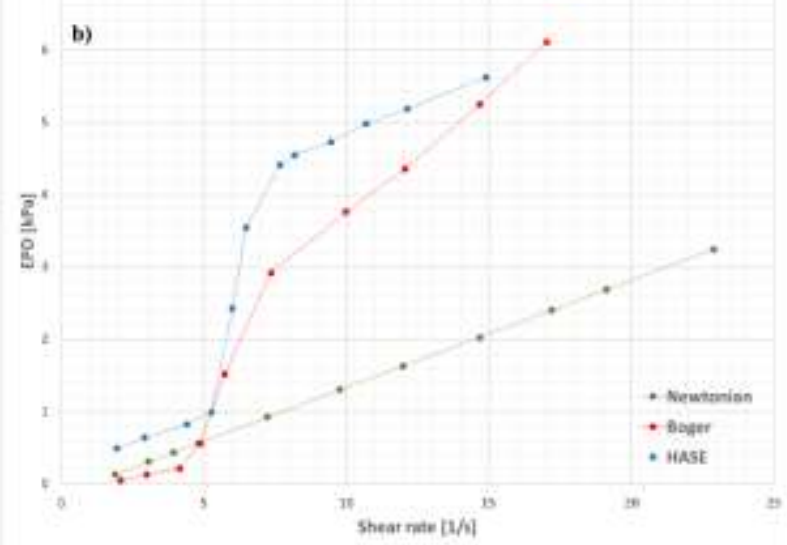

b) EPD VS SHEAR RATE

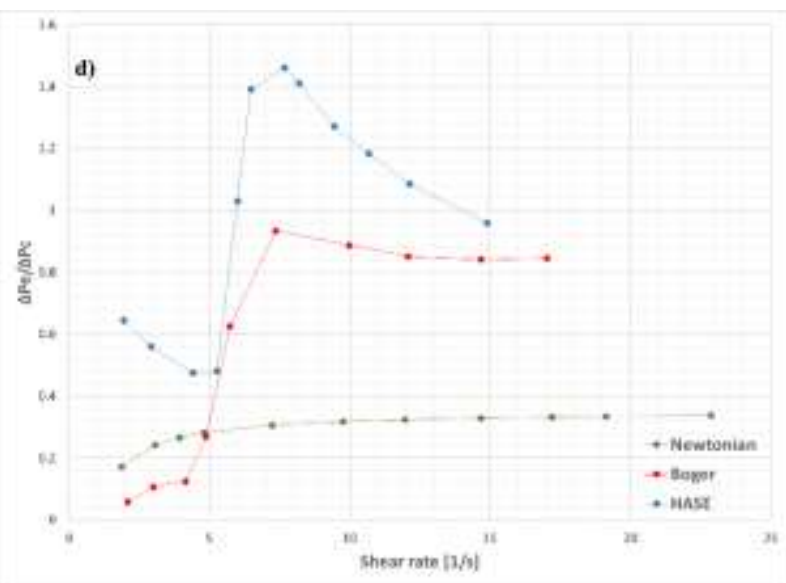

d) $\Delta \mathrm{Pe} / \Delta \mathrm{Pc}$ vs shear rate

f) Extensional/shear viscosity vs extensional/shear rate

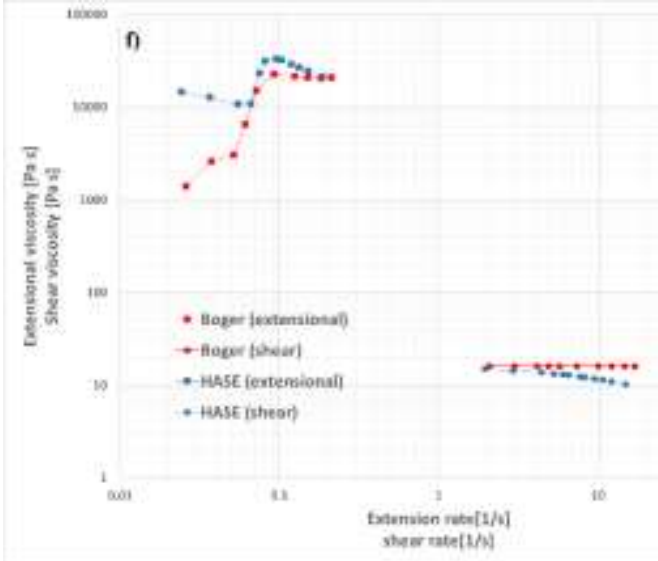

(c) 2020 EPRA IJRD | Journal DOI: https://doi.org/10.36713/epra2016 |www.eprajournals.com |85 | 


\section{EPRA International Journal of Research and Development (IJRD)

As a summary, it is observed that the flow dynamics in contraction consists of a coexistence between shear and extensional flows, presenting three main zones where the presence of one or another type of flow is predominant: The first zone has low flows, where there is a strong shear domain due to the effect of normal flow stresses of elastic origin, hindering extensional flow development and increasing the shear effect; at a certain critical interval of shear (4-6 s-1) or extension rate $(0.06-0.08 \mathrm{~s}-1)$ the extensional flow is the one that dominates the flow dynamics, and where extensional viscosity develops dramatically. The last zone, the increasing resistance to flow through a reduced cross-sectional area (viscous effect), generates a highly influential shear flow, gradually diminishing the extensional effect developed in the previous zone.

\section{Contraction 3:1:3 \\ Total pressure drop vs shear rate}

The graph of the total pressure drop (figure 5-a) shows a more differentiated behavior between the analyzed fluids: The critical shear rate appears at a lower value in the HASE solution (12-13 1/s) than the Boger fluid (20-21 1/s). Additionally, the pressure drop of the HASE solution descend again towards the Newtonian line at high shear rate, opposite case to Boger, whose upward trend remains similar to that presented in the previous contraction. These differences are caused by an increasing distance of the rheological properties between both fluids: while Boger maintains the same value of shear viscosity, the range of shear rate evaluated for the current contraction ratio causes the HASE solution to exhibit a decreasing viscosity, according to the rheogram presented in figure 3 . Although the shear viscosity of the HASE solution decreases, the extensional effect is still present in the flow dynamics.

\section{-Excess pressure drop vs shear rate}

For the current case (figure 5-b), an approaching of the EPD values of the HASE solution to the Newtonian reference line is observed; while in the case of the Boger fluid, the curve under the reference line is much clearer, showing an effect of the first difference of normal stresses more intense than in the previous contraction ratio; both situations indicate the development of shear flow effects greater than those generated by the contraction ratio $2: 1: 2$; by presenting a larger fluid/wall contact surface, such as a smaller cross-sectional area (Table 1), developing pressure drops greater than that of the previous case observed.

-Dimensionless excess pressure drop vs shear rate

The dimensionless EPD makes the development of the first normal stress difference more evident at low shear rate values (Figure 5-c); where the elastic effect in radial direction (greater than that generated by 2: 1:2 contraction) gradually increases to the point where the extensional effect exceeds it. This behavior shows that, as the elasticity develops in the radial direction with intensity, the elastic effect in the axial direction must develop by an equivalent amount (and even greater) in response to the changes in the contraction ratio. 


\section{EPRA International Journal of Research and Development (IJRD)}

Volume: 5 | Issue: 12 | December 2020

FIGURE 5. EXPERIMENTAL RESULTS - CONTRACTION/EXPANSION 3:1:3

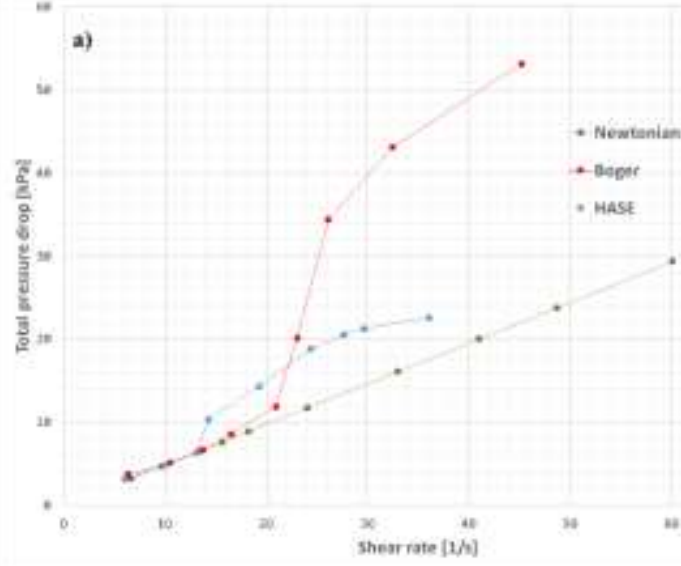

a) Total pressure drop vs shear rate

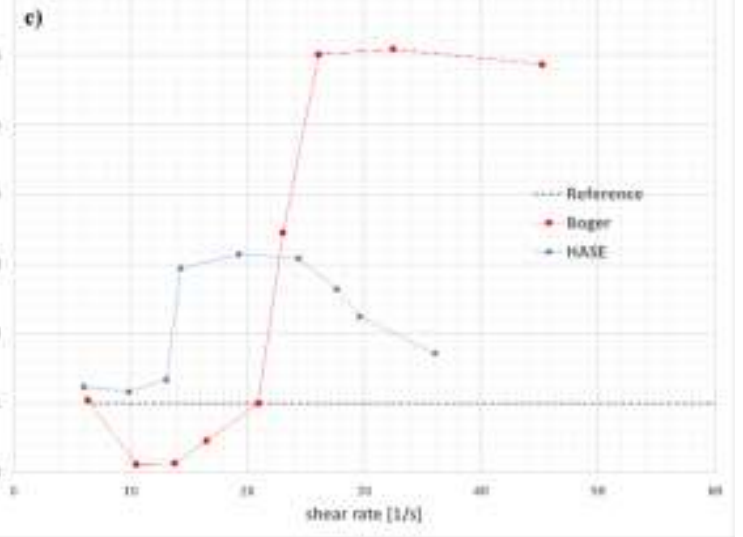

c) dimensionless EPD vs shear rate

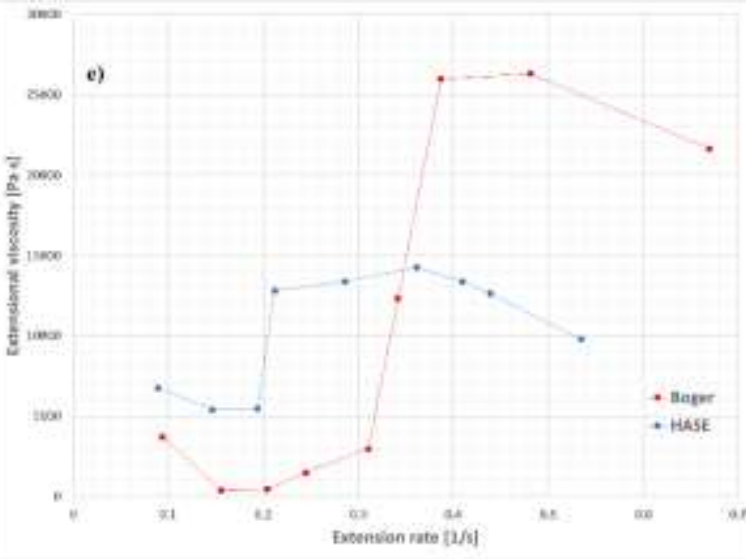

e) Extensional viscosity vs extensión rate

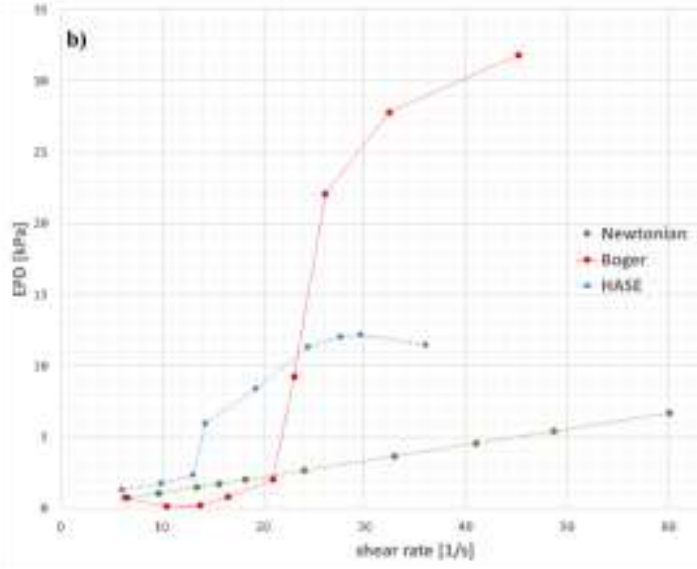

b) EPD vs shear rate

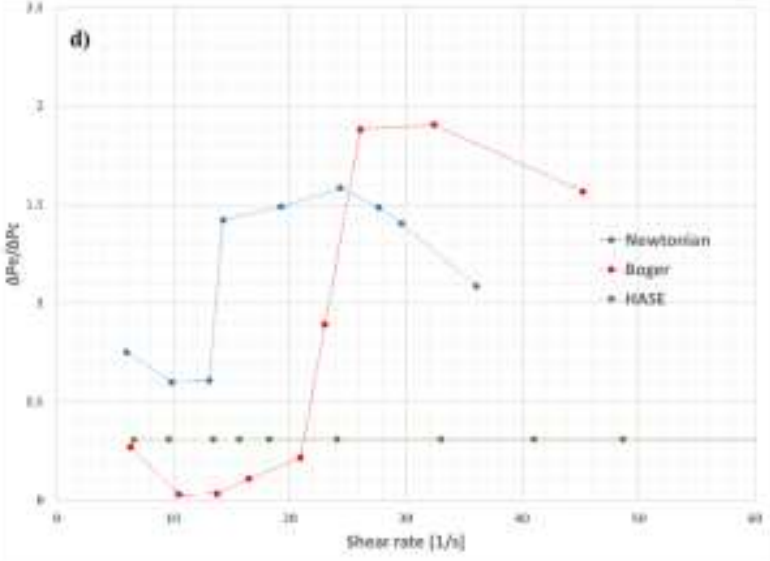

d) $\Delta \mathrm{Pe} / \Delta \mathrm{Pc}$ vs shear rate

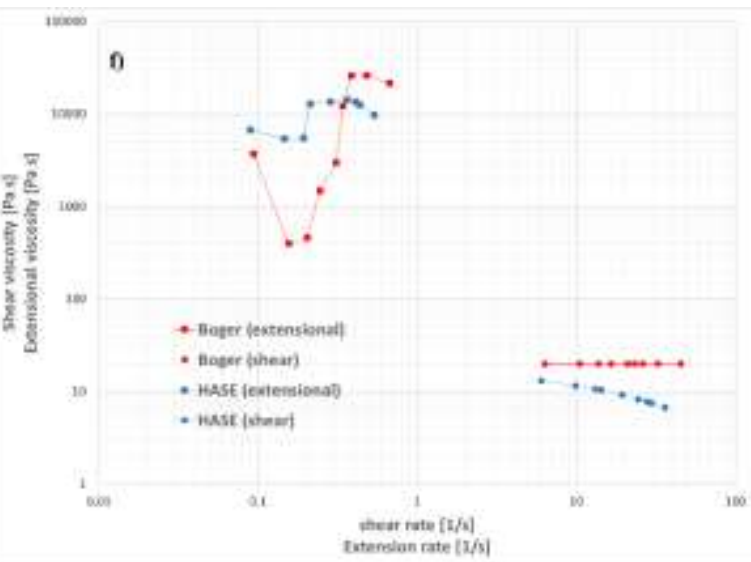

f) Extensional/shear viscosity vs extensional/shear rate 
Figure 5-d confirms the increase in extensional and shear effects. In the particular case of the HASE solution, the dimensionless pressure drop values (figure $5-\mathrm{c}$ and 5-d) are lower than those generated by the previous contraction. The growth of the effects of shear flow by increasing the contraction ratio, result in changes in the value of shear viscosity in this type of fluid, so the values represented are no longer comparable with respect to the shear viscosity of both the Boger fluid as the reference Newtonian (16 Pa s) since it flows at a lower shear viscosity. The observed extensional effects must be considered as an elastic manifestation at these low viscosity conditions, which are still of considerable value. This predominance is also evident in the Boger fluid, even when the viscosity does not decrease in this fluid, with a more abrupt decrease being observed after the critical zone.

\section{Extensional viscosity $v$ s extension rate}

The behavior of the extensional viscosity (figure 5 -e) agrees with the three main zones of flow dynamics observed both in this contraction relationship and in the previous one, the main difference being the drastic decrease in the extensional viscosity of the Boger fluid a low shear rate, an indication of the increase in shear effects, to the point of inhibiting the development of extensional flow. From the critical shear rate, a notable growth of extensional viscosity is observed at values higher than those reached by the 2:1:2 contraction, to finally descend to high shear rate. In the case of the HASE solution, the maximum value of extensional viscosity is lower than that generated in the previous contraction and the growth of extensional viscosity is not as noticeable, as it refers to a lower shear viscosity.
In general, the flow interval where there is extensional predominance is decreasing; the effect of shear flow begins to have a greater influence on the elastic extensional flow in the flow dynamics.

To recapitulate, the decrease in the minimum radius of the hyperbolic contraction zone generates changes such as to cause an increase in both the extensional and shear effects in the flow dynamics. However, the zones of shear or extensional dominance, defined in the contraction ratio $2: 1: 2$, are valid for the current contraction ratio, increasing the degree of competition between the different types of flow.

\section{Contraction 4:1:4 \\ Total pressure drop $v$ s shear rate}

For the current contraction ratio there is a considerable increase in the pressure drops generated by the Boger fluid geometry, exceeding the measurement range of the sensors, generating anomalous pressure drops at high flows, so from this contraction ratio the number of points evaluated is lower than in the cases previously analyzed (figure 6a). The initial points of the Boger fluid lie above the Newtonian line, so that for this contraction ratio there is from the beginning an important elastic contribution to the flow generated; on the other hand, the shear effect has experienced an important increase, so much so that for the HASE solution, there are points below the Newtonian line, indicating very low values of shear viscosity. The critical shear rate is manifested first in the Boger fluid (28-30 s-1), followed by HASE (36-38 $\mathrm{s}-1)$, reverse case of the $3: 1: 3$ contraction. 
FIGURE 6. EXPERIMENTAL RESULTS - CONTRACTION/EXPANSION 4:1:4

a) Total pressure drop vs shear rate

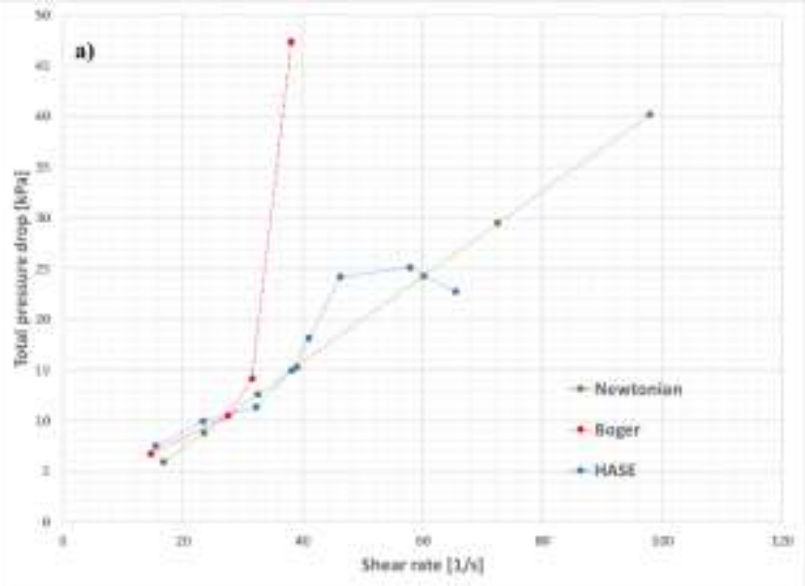

c) dimensionless EPD vs shear rate

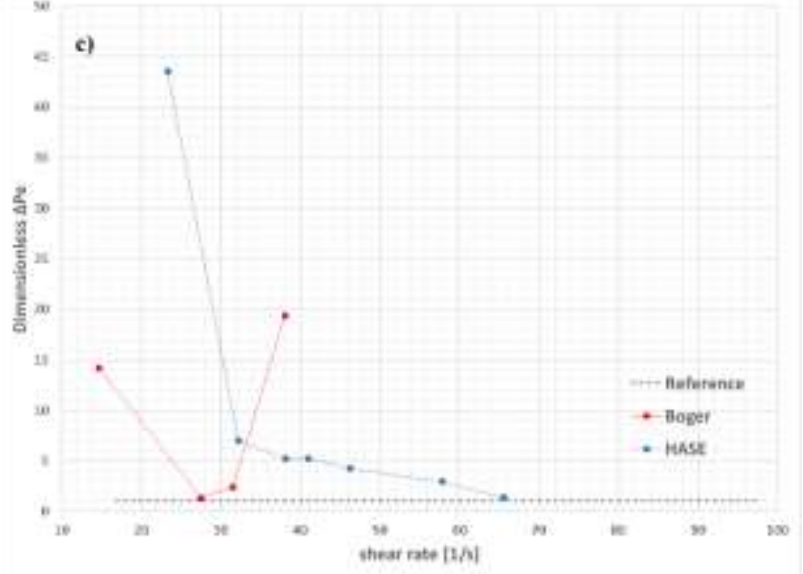

e)Extensional viscosity vs extensión rate

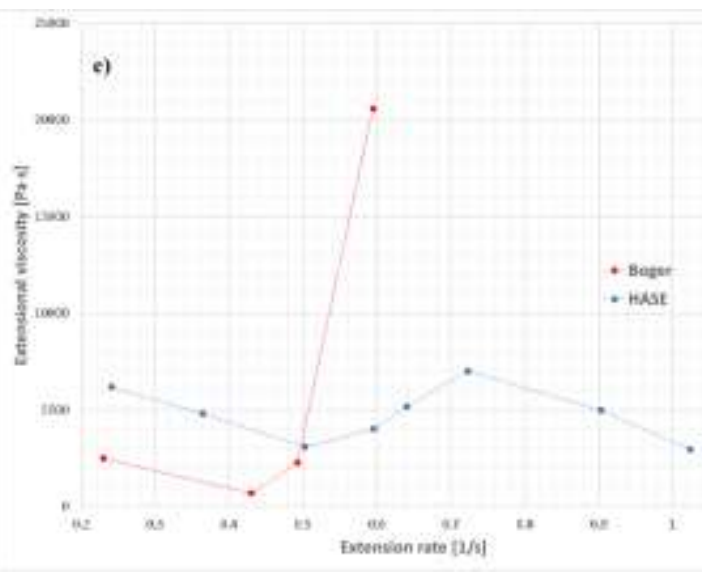

b) EPD vs shear rate

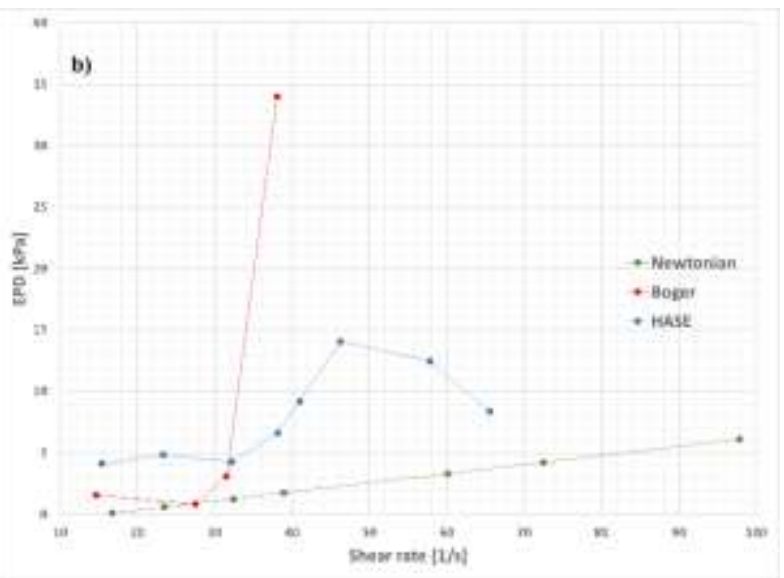

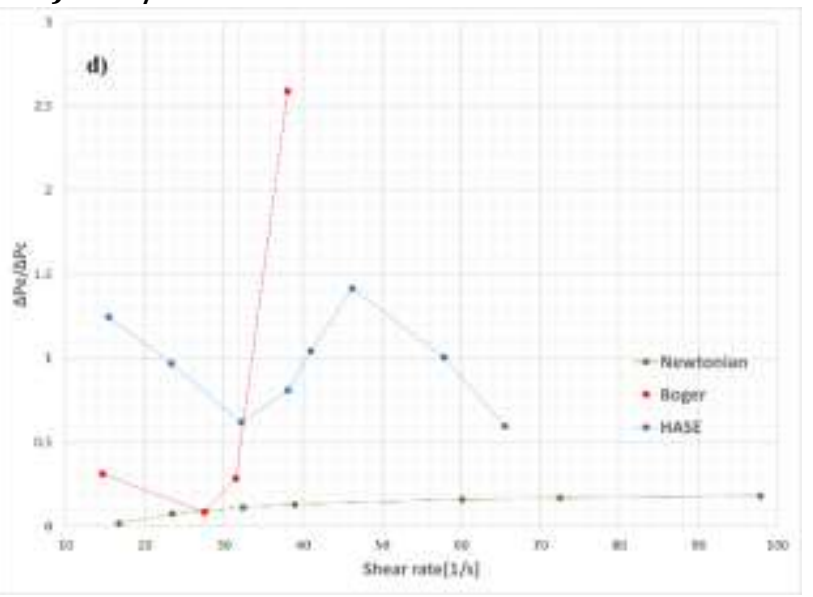

f) Extensional/shear viscosity vs extensional/shear rate

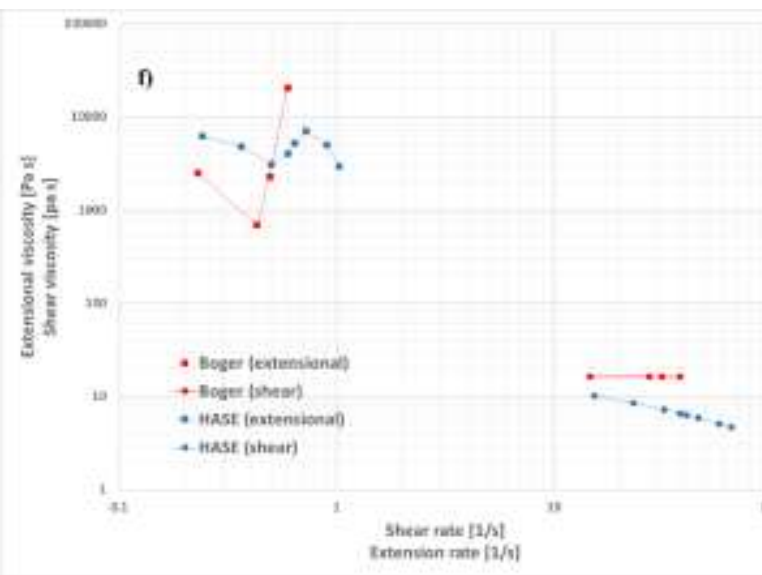




\section{SJIF Impact Factor: 7.001| ISI I.F.Value:1.241| Journal DOI: 10.36713/epra2016 ISSN: 2455-7838(Online) EPRA International Journal of Research and Development (IJRD)}

\section{Excess pressure drop $v$ s shear rate}

In figure 6-b, the HASE solution is above the Newtonian line throughout the experimental range, exhibiting very high values, considering that, at the evaluated shear speed values, the shear viscosity of this fluid is approximately half from its original value (figure 3). the extensional dominance zone does not manifest itself with the intensity observed in the previous contraction ratios, its interval of influence wider than the present one. The effect of shear flow even begins to hinder the development of extensional flow.

In Boger fluid, the development of elasticity is such that the effect of the first normal stress difference no longer appears below the Newtonian line, presenting a slight decrease before the critical shear rate: The elastic effect in axial and radial direction are strong enough so that their effects are above the Newtonian shear reference. Unfortunately, the operating limit of the equipment makes it difficult to determine the behavior of the flow beyond this point and whether the latest evaluation corresponds to the maximum extensional manifestation developed by the flow.

\section{Dimensionless excess pressure drop vs shear rate}

The dimensionless graphs corresponding to this contraction ratio show a considerable development of elasticity in the flow range studied, and an increasing shear effect. For the dimensionless excess pressure drop (figure 12-c), all the values obtained for both fluids exceed the reference line. It is interesting to note the behavior of the line corresponding to the HASE solution the initial point shows a maximum development of elasticity (even higher than that generated by the Boger fluid in all the experimental runs analyzed), descending to values near the Newtonian reference. The Boger fluid the effect of the first normal stress difference in shear occurs in a relatively small range of shear rate values; the elastic effect in the radial direction is quickly exceeded by that extension in the flow direction, although higher than the reference values.

The EPD ratio versus the pressure drop generated by the hyperbolic geometry (figure 6-d) provides a more explicit way to quantify the degree of competition between shear and extensional flow, since it considers the variation of the shear viscosity of the fluids with the shear rate, and shows the areas of shear and extensional predominance not entirely clear in the previous graphs. The HASE solution experiences obvious competition between extensional and shear flows and the areas where one or the other type of flow is dominant are clearly recognizable. However, the recorded values are lower than those developed by the 2:1:2 and $3: 1: 3$ contraction ratios.

\section{Extensional viscosity $v$ s extension rate}

The extensional viscosity values again show a downward trend as the contraction ratio increases; the extensional flow is increasingly hampered by the development of shear flow. Further experimentation is necessary to determine whether the maximum point present in the case of Boger fluid represents the maximum extension developed by the fluid in this contraction relationship (Figure 6-e).

\section{Contraction 5:1:5 \\ Total pressure drop vs shear rate}

For the last contraction ratio to be analyzed in this work, which presents the smallest dimensions in both length and cross-sectional area, in the case of the total pressure drop (figure 13-a), the absence of behaviors close to the Newtonian fluid line and, therefore, there is no critical shear rate to apply in this case. The absence of a critical shear rate is caused by a bias in the flow interval caused by the operating limitations of the experimental device, which does not allow knowing with certainty the flow dynamics zone where the exposed values are found.

The shear effect generated by the geometry is of such intensity that it takes the line of the HASE solution below the Newtonian line, since under these conditions its shear viscosity is much lower. The Boger fluid experiences a proportional rise throughout the experimentation interval, with behavior like that analyzed in the previous contraction ratios at high flows (outside the critical zone)

\section{Excess pressure drop $v$ s shear rate}

For the EPD and dimensionless EPD graphs (figures 6-b and 6-c), the development of the extensional flow by the two fluids is observed, where the curve generated by HASE is smaller than due to the shear viscosity changes developed, and where the Boger fluid shows an upward trend as the flow increases. The location of these values with respect to the previously exposed zones of flow dynamics is unknown.

\section{Dimensionless excess pressure drop vs shear rate}

When analyzing the dimensionless parameter $\Delta \mathrm{Pe} / \Delta \mathrm{Pc}$ (figure 6-d) it shows that, although the hyperbolic contraction zone generates extensional flows of considerable magnitude, the shear effects generated in response are also increased, decreasing the extensional effect when increasing the flow. This behavior is reflected in the change in trend of the lines in figure 5-d with respect to those generated in figures 6-b and 6-c. The $\Delta \mathrm{Pe} / \Delta \mathrm{Pc}$ ratio represents a more 


\section{EPRA International Journal of Research and Development (IJRD)}

Volume: 5 | Issue: 12 | December 2020

- Peer Reviewed Journal

adequate way to represent the competition between shear and extensional flows with respect to dimensionless quantities used in previous studies.

\section{Viscosidad extensional vs rapidez de} extensión

The extensional viscosity (Figure 6-e) decreases slowly with increasing flow. It is interesting to observe the behavior of the shear and extensional viscosities for the fluids Boger and HASE (figure 6-f) have a similar trend.

FIGURE 6. EXPERIMENTAL RESULTS - CONTRACTION/EXPANSION 5:1:5

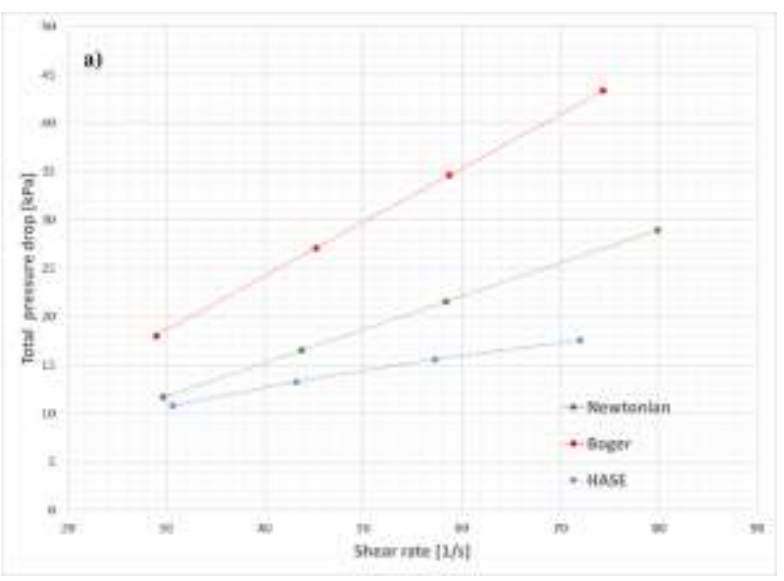

a) Total pressure drop vs shear rate

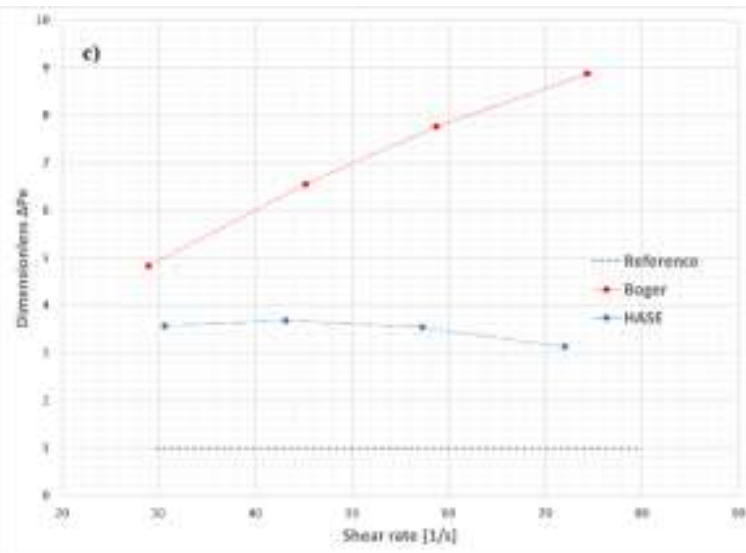

c) dimensionless EPD vs shear rate

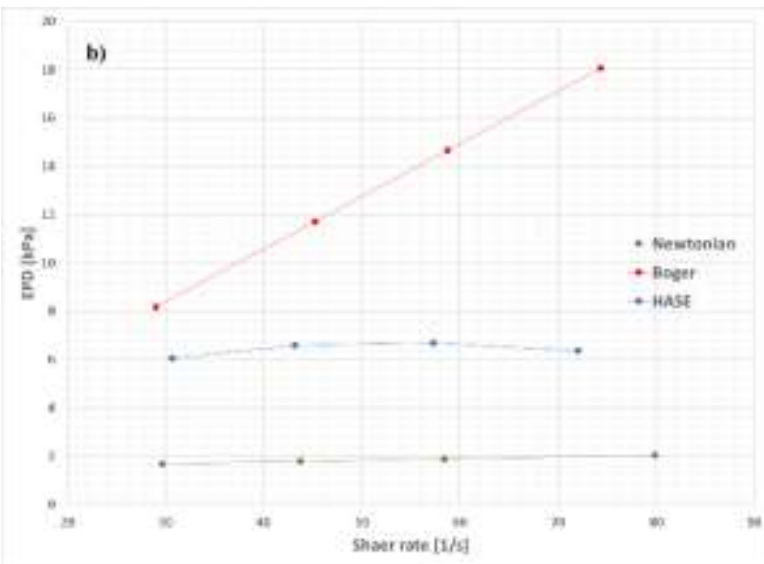

b) EPD vs shear rate

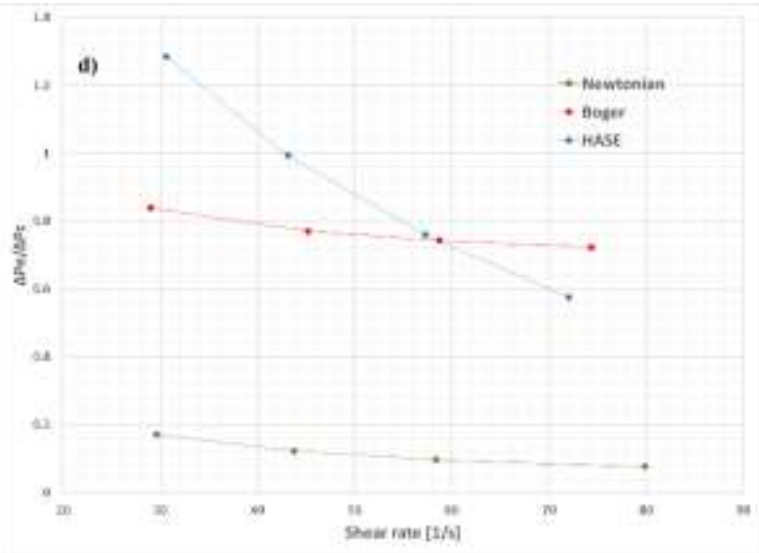

d) $\Delta \mathrm{Pe} / \Delta \mathrm{Pc}$ vs shear rate 


\section{EPRA International Journal of Research and Development (IJRD)}

Volume: 5 | Issue: 12 | December 2020

- Peer Reviewed Journal

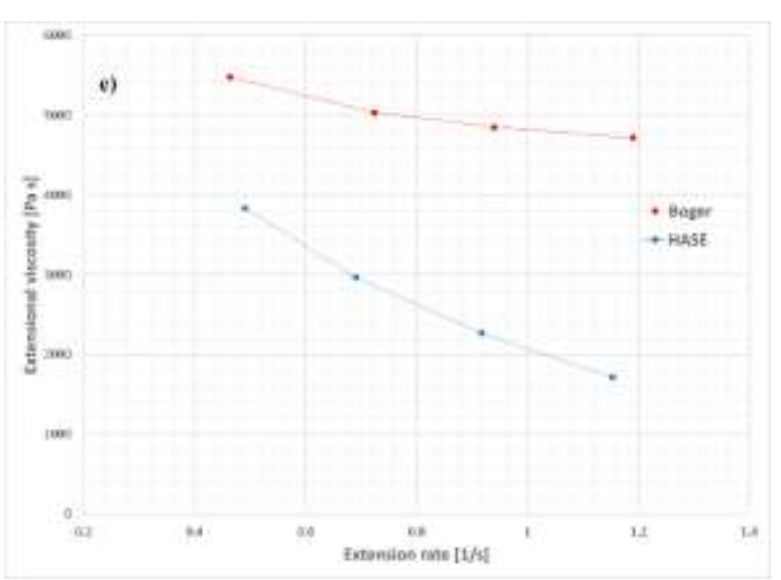

e) Extensional viscosity vs extensión rate

\section{CONCLUSIONS}

The Hagen-Poiseuille type theoretical expression in a system in hyperbolic contraction/expansion predicted with great precision the value of the pressure drop (especially at low flows, where no additional effects are present), in the same way, the value of the Excess pressure drop (EPD), represented the elastic component of the analyzed fluids, which allowed us to recognize the competition between the extensional and shear flow.

For low contraction ratios (such as 2:1:2 and $3: 1: 3$ ) there was a flow dynamics defined by three main zones:

at low flows, there is a predominance of shear flow, due to the development of an elastic response in radial direction by the fluids. The effect of the first difference of normal stresses in shear becomes evident, appearing more clearly than in the case of sudden axisymmetric geometries.

The second zone extends from the critical shear rate, where the extensional flow occurs with greater intensity (which is also expressed in the pressure drop), up to a maximum point, related to the maximum extension of the fluid element. this zone tends to decrease as the contraction ratio increases.

The last zone once again presents characteristics mainly of shear flow, related to the interactions of the fluid with the walls of the contraction. The shear effect on the flow causes changes in the viscosity in the specific case of the HASE solution, where this behavior, beyond being caused by the competition initially posed between the extensional and shear flows, is considered a direct consequence of the shear flow.

For the large contraction ratios $(4: 1: 4$ and 5:1:5), the operating limitations of the equipment prevented the previously exposed areas from being fully

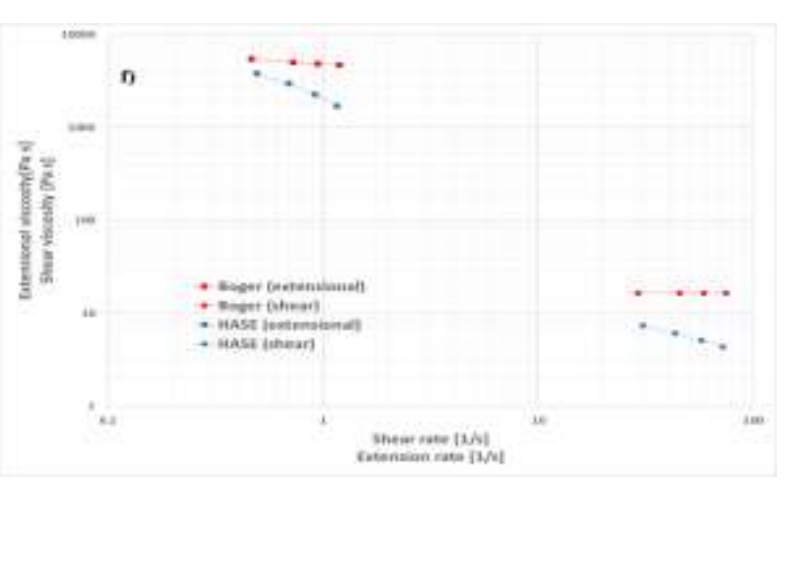

f) Extensional/shear viscosity vs extensional/shear rate

observed, restricting themselves to limited sections of them. A proportional trend is observed when increasing the contraction ratio of the extensional and shear effects, where the latter are those that impose their characteristics on the flow.

The extensional viscosity values obtained were of an order like those reported in the literature, and their behavior faithfully represents the ranges of flow dynamics previously exposed, increasing the value of this property drastically in the extensional zone.

Some of the main future achievements of this work lie in the extension of the equipment's operating interval, which will allow the flow dynamics to be analyzed with greater accuracy in high contraction ratios, as well as to analyze experimental cases outside the steady state (as can be the pulsatile flow), and to be able to approach real flow situations.

\section{Acknowledgments}

This research work had the support of the Support Program for Research and Technological Innovation Projects (PAPIIT) UNIVERSIDAD NACIONAL AUTÓNOMA DE MÉXICO Mexico $<<$ IA106818>>

\section{BIBLIOGRAPHIC REFERENCES}

1. AGUAYO J.P., TAMADDON-JAHROMI H.R., WEBSTER M.F. "EXCESS PRESSURE DROP ESTIMATION IN CONTRACTION AND EXPANSION FLOWS FOR CONSTANT SHEAR-VISCOSITY, EXTENSION STRAIN-HARDENING FLUIDS" J. NON-NEWTONIAN FLUID MECH. 153 (2008) 157-176

2. ANNA, S.L., MCKINLEY G.H, NGUYEN D.A., SRIDHAR T., MUller S.J., HuanG J., James D.F, “AN INTERLABORATORY COMPARISON OF MEASUREMENTS FROM FILAMENT STRETCHING AND BREAKUP OF MODEL ELASTIC LIQUIDS”' J. RHEOL. 45 (2000) 83-114 


\section{SJIF Impact Factor: 7.001| ISI I.F.Value:1.241| Journal DOI: 10.36713/epra2016 ISSN: 2455-7838(Online) EPRA International Journal of Research and Development (IJRD)}

3. Barnes, H. A., Hutton J.F., Walters K. "AN INTRODUCTION TO RHEOLOGY" RHEOLOGY SERIES VOL. 3 ELSEVIER, THE NETHERLANDS (1989)

4. Bautista F. de Santos J.M, Puig J.E., Manero O. UNDERSTANDING THIXOTROPIC AND ANTITHIXOTOPIC BEHAVIOR OF VISCOELASTIC MICELLAR SOLUTIONS AND LIQUID CRYSTALLINE DISPERSIONS, J. NON-NEWTONIAN FLUID MECH. 80 (1999) 93-113.

5. BINDING D.M., "FURTHER CONSIDERATIONS OF AXISYMMETRIC CONTRACTION FLOWS", J. NON-NEWTONIAN FLUID MECH. 41 (1991) 27-42.

6. BINDING DM, WALTERS $K$ "ON THE USE OF FLOW THROUGH A CONTRACTION IN ESTIMATING THE EXTENSIONAL VISCOSITY OF MOBILE POLYMER SOLUTIONS". J NON-NEWTONIAN FLUID MECH 30(23) (1988):233-250

7. BIRD R. B. BYRON, W.E, ARMSTRONG R. C., HASSAGER O. "DYNAMICS OF POLYMERIC LIQUIDS, VOLUME 1: FLUID MECHANICS” WILEY (1987)

8. BIRD, R., BYRON, W.E., STEWART, E.N., LIGHTFOOT. "TRANSPort Phenomena". John Wiley \& SONS. (1960)

9. Boger D.V. "VISCOELASTIC FLOWS ThROUGH CONTRACTIONS” ANN. REV. FLUID MECH. (1987). 19,157-182

10. Cable P.J. and Boger D.V. "A Comprehensive EXPERIMENTAL INVESTIGATION OF TUBULAR ENTRY FLOW OF VISCOELASTIC FLUIDS, PART I. VORTEX CHARACTERISTIC IN STABLE FLOW", AICHE JOURNAL. 24 (1978) 869.

11. Cable P.J. AND Boger D.V., “A Comprehensive EXPERIMENTAL INVESTIGATION OF TUBULAR ENTRY FLOW OF VISCOELASTIC FLUIDS, PART II. VORTEX CHARACTERISTIC IN STABLE FLOW", AICHE JOURNAL. 24 (1978) 992.

12. CaMPo-DEAÑo L., Galindo-Rosales F.J., Pinho F.T, ALVES M.A., OLIVEIRA M. S.N. (2011) "FLOW OF LOW VISCOSITY BOGER FLUIDS THROUGH A MICROFLUIDIC HYPERBOLIC CONTRACTION" J. NONNEWTONIAN FLUID MECH. 166 1286-1296.

13. Cártalos U. and J.M. Piau J.M., "CREeping Flow REGIMES OF LOW CONCENTRATION POLYMER SOLUTIONS IN THICK SOLVENTS THROUGH AN ORIFICE DIE", J. NON-NEWTONIAN FLUID MECH. 45 (1992) 231-285.

14. CHANDRASHEKHAR D., KUMAR S., (2016) "EFFECTS OF AXIALLY SYMMETRIC STENOSIS ON THE BLOOD FLOW IN AN ARTERY HAVING MILD STENOSIS" INTERNATIONAL JOURNAL OF MATHEMATICS TRENDS AND TECHNOLOGY (IJMTT) VOL 35 \#3

15. COGSWELL F.N., CONVERGING FLOW AND STRETCHING FLOW: A COMPILATION, J. NON-NEWTONIAN FLUID MECH. 4 (1978) 23-38.

16. FEIGL K., TANNER F. X. EDWARDS B. J., COLLIER J. R., "A NUMERICAL STUDY OF THE MEASUREMENT OF ELONGATIONAL VISCOSITY OF POLYMERIC FLUIDS IN A SEMIHYPERBOLICALLY CONVERGING DIE” J. NONNEWTONIAN FLUID MECH. 115 (2003) 191-215

17. JAMES F. D., "FLOW IN A CONVERGING CHANNEL AT MODERATE REYNOLDS NUMBERS" AICHE JOURNAL VOL. 37 NO. 1 (1991)
18. JAMES F. D., CHANDLER G. M., “A CONVERGING CHANNEL RHEOMETER FOR THE MEASUREMENT OF EXTENSIONAL VISCOSITY" J. NON-NEWTONIAN FLUID МЕСH. 35 (1990) 421-443

19. MACOSKO, C. W. "RHEOLOGY: PRINCIPLES, MEASUREMENTS AND APPLICATIONS" (1994)

20. MEISSNER J. "EXPERIMENTAL ASPECTS IN POLYMER MELT ELONGATIONAL RHEOMETRY," CHEM, ENG. COMMUN. (1985), 159-180

21. MUÑOZ K. D. “COMPARATIVE EXPERIMENTAL STUDY OF FLOW DYNAMICS IN CONTRACTION/EXPANSION IN AXISYMMETRIC AND SQUARE GEOMETRICS FOR COMPLEX FLUIDS”. THESIS TO OBTAIN THE DEGREE OF CHEMICAL ENGINEER UNAM, MÉXICO (2017).

22. NGUYEN G.H. AND BOGER D.V., "THE KINEMATICS AND STABILITY OF DIE ENTRY FLOWS”, J. NONNEWTONIAN FLUID MECH. 5 (1979) 353-368.

23. NYSTRÖM M., TAMADDON-JAHROMI H.R., STANDING M., WEBSTER M.F., (2016) "EXTRACTING EXTENSIONAL PROPERTIES THROUGH EXCESS PRESSURE DROP ESTIMATION IN AXISYMMETRIC CONTRACTION AND EXPANSION FLOWS FOR CONSTANT SHEAR VISCOSITY, EXTENSION STRAIN-HARDERING FLUIDS" RHEOL. ACTA. 55 (2016) 373-396

24. Ober T.J., HaWard S.J., PiPe C.J., Soulages J., MCKINLEY G.H., (2013) "MICROFLUIDIC EXTENSIONAL RHEOMETRY USING A HYPERBOLIC CONTRACTION GEOMETRY". RHEOL. ACTA. 52 529-546.

25. OLIVEIRA M.S.N., ALVES M.A., MCKINLEY G.H., PINHO F.T, (2006) "EXTENSIONAL FLOW THROUGH MICROFABRICATED HYPERBOLIC CONTRACTIONS" CONFERÊNCIA NACIONAL DE MÉTODOS NUMÉRICOS EM MECÂNICA DOS FLUIDOS E TERMODINÂMICA PORTUGAL

26. PÉREZ M., "EXPERIMNTAL STUDY OF COMPLEX FLUIDS IN CONTRACTION/EXPANSION FLOW”. THESIS TO OBTAIN CHEMINCA ENGINEERING PHD DEGREE. UNAM, MÉXICO (2016).

27. PETRIE C.J. S., "EXTENSIONAL VISCOSITY: A CRITICAL DISCUSSION” J. NON-NEWTONIAN FLUID MECH. 137 (2006) 15-23

28. QUEZADA A.P., “EXPERIMENTAL EVALUATION OF UNIAXIAL EXTENSIONAL VISCOSITY FROM A RECTANGULAR CONTRACTION-EXPANSION FLOW USING VISCOELASTIC COMPLEX FLUIDS." THESIS TO OBTAIN THE DEGREE OF CHEMICAL ENGINEER UNAM, MÉXICO (2017).

29. RAJAGOPALAN D. (2000) "COMPUTATIONAL ANALYSIS OF TECHNIQUES TO DETERMINE EXTENSIONAL VISCOSITY FROM ENTRANCE FLOWS". RHEOL ACTA 39:138-151

30. ROTHSTEIN J.P., MCKINLEY G.H., "THE AXISYMMETRIC CONTRACTION-EXPANSION: THE ROLE OF EXTENSIONAL RHEOLOGY ON VORTEX GROWTH DYNAMICS AND THE ENHANCED PRESSURE DROP", J. NON-NEWTONIAN FLUID MECH. 98 (2001) 33-63.

31. SAMPSON R.A; ON STOKES'S CURRENT FUNCTION, PhILOSOPHICAL TRANSACTIONS OF THE ROYAL SOCIETY OF LONDON A; VOL 182 (1891) 449-518.

32. SOCHI T. "THE FLOW OF NEWTONIAN FLUIDS IN AXISYMMETRIC CORRUGATED TUBES” UNIVERSITY COLLEGE LONDON (2010) 


\section{EPRA International Journal of Research and Development (IJRD)

33. Sousa P., Pinho T., Oliveira M., Alves, A., (2011) "EXTENSIONAL FLOW OF BLOOD ANALOG SOLUTIONS IN MICROFLUIDIC DEVICES” BIOMICROFLUIDICS 5014108

34. Sousa P., Pinho T., Oliveira M., Alves, A., "Flow OF A BLOOD ANALOGUE SOLUTION THROUGH MICROFABRICATED HYPERBOLIC SOLUTIONS", COMPUTATIONAL VISION AND MEDICAL IMAGE PROCESSING (2010) 265-279

35. SRIVASTAVA V.P, “ARTERIAL BLOOD FLOW THROUGH A NONSYMMETRICAL STENOSIS WITH APPLICATIONS” JPN. J. APPL. PHYS. VOL.34 (1995) 6539-6545

36. TABATABAEI S., LÓPEZ AGUILAR J.E., TAMADDONJAHROMI H.R., WEBSTER M.F., WILLIAMS R., (2015) "MODIFIED BAUTISTA-MANERO (MBM) MODELING FOR HYPERBOLIC CONTRACTION-EXPANSION FLOWS” RHEOL. ACTA 54 869-885

37. TREJO E., "EXTRACCIÓN SELECTIVA COMO UN NUEVO MÉTODO PARA MEDIR VISCOSIDAD EXTENSIONAL” TESIS PARA OBTENER EL GRADO DE INGENIERO MECÁNICO. UNAM, FACULTAD DE INGENIERÍA. (2013)

38. WALTERS K., TAMADDON-JAHROMI H.R, WEBSTER M.F., TOMÉ M.F., S MCKEE, "THE COMPETING ROLES OF EXTENSIONAL VISCOSITY AND NORMAL STRESS DIFFERENCES IN COMPLEX FLOWS OF ELASTIC LIQUIDS", KOREA-AUSTRALIA RHEOLOGY JOURNAL 21 (4) (2009) 225-233.

39. WANG J., JAMES F. D. "LUBRICATED EXTENSIONAL FLOW OF VISCOELASTIC FLUIDS IN A CONVERGENT MICROCHANNEL”'J. RHEOL. 55 (2011) 1103-1126

40. White J. L., KONDO A. "FLOW PATTERNS IN POLYETHYLENE AND POLYSTYRENE MELTS DURING EXTRUSION THROUGH A DIE ENTRY REGION: MEASUREMENT AND INTERPRETATION" J. NONNEWTONIAN FLUID MECH. 3 (1977) 41-64

41. Yaginuma T., OliveiRa M., Lima R., ISHikaWa T., YAMAGUCHI T., (2013) "HUMAN RED BLOOD CELL BEHAVIOR UNDER HOMOGENEOUS EXTENSIONAL FLOW IN A HYPERBOLIC-SHAPED MICROCHANNEL" BIOMICROFLUIDICS 7054110

\section{SYMBOLOGY}

$\underline{\underline{D}} \quad$ Strain rate tensor (vector notation)

$\bar{D}_{1} \quad$ Diameter before contraction

$D_{2} \quad$ Diameter after contraction

$\mathrm{L} \quad$ Tube length

$N_{1} \quad$ First difference of normal stresses

Q Volumetric flow

$r_{1}, r_{\max } \quad$ Radius maximum before contraction

$r_{2}, r_{\min } \quad$ Radio minimum after contraction

$\underline{\underline{T}}$

$\bar{V}_{1}, V_{2}$

$\underline{\underline{\underline{W}}}$

$\overline{\dot{\gamma}}$

$\Delta P$

$\Delta P_{T}$

$\Delta P_{c}$

$\Delta P_{e}$

$\underline{\Delta v}$

$\dot{\varepsilon}$

$\varepsilon_{h}$

$\eta$

$\eta_{e}$

$\mu$

$\tau_{z z}, \tau_{x x}$
Stress tensor (vector notation)

Sensor voltages

Vorticity (vector notation)

Shear rate

Pressure drop

Total pressure drop

Pressure drop in contraction zone

Excess pressure drop (EPD)

Velocity gradient

extension rate

Hencky's extension

Shear viscosity

Extensional viscosity

Newtonian shear viscosity

Normal components of the stress tensor 